\title{
Electrical resistivity imaging for monitoring soil water motion patterns under different drip irrigation scenarios
}

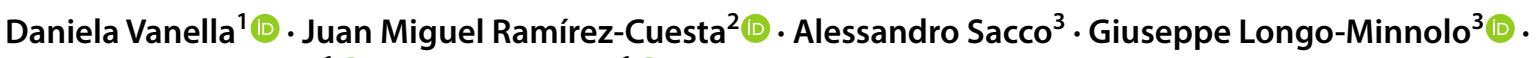 \\ Giuseppe Luigi Cirelli ${ }^{1}$ (ए) Simona Consoli ${ }^{1}$ (1)
}

Received: 20 December 2019 / Accepted: 12 September 2020 / Published online: 25 September 2020

(c) The Author(s) 2020

\begin{abstract}
The use of hydrogeophysical methods provides insights for supporting optimal irrigation design and management. In the present study, the electrical resistivity imaging (ERI) was applied for monitoring the soil water motion patterns resulting from the adoption of water deficit scenarios in a micro-irrigated orange orchard (Eastern Sicily, Italy). The relationship of ERI with independent ancillary data of soil water content (SWC), plant transpiration $(T)$ and in situ measurements of hydraulic conductivity at saturation $\left(K_{\mathrm{s}}\right.$, i.e., using the falling head method, $\left.\mathrm{FH}\right)$ was evaluated. The soil water motion patterns and the maximum wet depths in the soil profile identified by ERI were quite dependent on SWC $\left(R^{2}=0.79\right.$ and 0.82 , respectively). Moreover, ERI was able to detect $\mathrm{T}$ in the severe deficit irrigation treatment (electrical resistivity increases of about 20\%), whereas this phenomenon was masked at higher SWC conditions. $K_{\mathrm{s}}$ rates derived from ERI and FH approaches revealed different patterns and magnitudes among the irrigation treatments, as consequence of their different measurement scales and the methodological specificity. Finally, ERI has been proved suitable for identifying the soil wetting/drying patterns and the geometrical characteristics of wet bulbs, which represent some of the most influential variables for the optimal design and management of micro-irrigation systems.
\end{abstract}

Daniela Vanella

daniela.vanella@unict.it

Juan Miguel Ramírez-Cuesta

ramirezcuesta.jm@gmail.com

Alessandro Sacco

alessandro.sacco@unict.it

Giuseppe Longo-Minnolo

giuseppe.longominnolo@phd.unict.it

Giuseppe Luigi Cirelli

giuseppe.cirelli@unict.it

Simona Consoli

simona.consoli@unict.it

1 Dipartimento di Agricoltura, Alimentazione e Ambiente (Di3A), Università Degli Studi Di Catania, via S. Sofia 100 95123, Catania, Italy

2 Departamento de Riego, Centro de Edafología y Biología Aplicada del Segura (CEBAS-CSIC), P.O. Box 164, 30100 Murcia, Spain

3 International Doctorate in Agricultural, Food and Environmental Science, Di3A, University of Catania, Catania, Italy

\section{Introduction}

In semi-arid and arid regions, irrigation management practices depend on the accurate characterization of temporal and spatial soil water content (SWC) dynamics (Vereecken et al. 2008). In general, the soil texture and the soil hydraulic characteristics represent the two main drivers of SWC changes and soil water infiltration (Campbell and Norman 1998). Nowadays, the most common methods adopted to measure SWC distribution at the root-zone level (e.g., time domain and/or frequency domain sensors, neutron probes) present several limitations (Robinson et al. 2008). The main drawback of these SWC methods concerns their pointbased nature and specifically the non-representativeness and restricted sampling volume (i.e., $10-100 \mathrm{~cm}^{3}$ ). In addition, these measurements strongly depend on sensors location in the soil profile (e.g., Bogena et al. 2015; Robinson et al. 2008). Furthermore, their installation requires drilling that may cause disturbance of soil structure and water flow regime. However, even if the SWC variation is recognized as a proxy of soil water infiltration (Brindt et al. 2019), identifying water flow pathways due to irrigation in the unsaturated soil profile where plant roots are mainly distributed is 
a complex challenge (Guo et al. 2019; Zhang et al. 2017). In fact, very large variations in SWC exist throughout the root zone especially under localized irrigation (García-Tejera et al. 2017), mainly due to the preferential root growth in the wetted bulbs (Klepper 1991). Several methods have been developed and applied for the infiltration rates characterization. Specifically, the soil hydraulic conductivity at saturation $\left(K_{\mathrm{s}}\right)$ can be obtained by field and laboratory methods. In situ $K_{\mathrm{s}}$ measurements, based on constant head $(\mathrm{CH})$ or falling head $(\mathrm{FH})$ methods, are generally preferred instead of laboratory determinations. In fact, the small-sized soil samples handled in laboratory may not be representative of the field conditions (Ibrahim and Aliyu 2016). The high spatial and temporal variability of $K_{\mathrm{s}}$ requires, however, a huge number of field measurements for a comprehensive understanding of the infiltration process. Moreover, it is known that the different in situ $K_{\mathrm{s}}$ methods provide distinct infiltration rates even under the same soil conditions (Guo et al. 2019).

The use of hydrogeophysical methods may contribute to solve some of the above-mentioned limitations for capturing lateral SWC changes and potentially for determining the relative soil water motion. It has been demonstrated how especially electrical resistivity (ER) methods, such as electrical resistivity tomography (ERT) or electrical resistivity imaging (ERI), can successfully image the SWC dynamics, as a derived soil property (e.g.,Bertermann and Schwarz 2018; Binley et al. 2015; Robinson et al. 2012; Schwartz et al. 2008). Moreover, ER surveys involve the use of several electrodes in galvanic contact with the soil surface and/or subsurface, which allows significant flexibility for the configuration of ER acquisitions at the field scale (Binley et al. 2015). Even though, the most suitable ER configuration needs to be tailored as function of the target problem, and in terms of sensitivity (e.g., horizontal and vertical scales) that can be practically achieved (Ronczka et al. 2015). In this sense, recent ER applications have been conducted in micro-irrigated field conditions for evaluating the wetted fraction area and the irrigation fronts (e.g.,Cassiani et al. 2015; Hardie et al. 2018; Moreno et al. 2015; Vanella et al. 2018, 2019). Moreover, the rapid development of timelapse ER measurement systems permits to explore the time domain of eco-hydrological dynamics processes with high accuracy (e.g.,Jayawickreme et al. 2014; Singha et al. 2015; Williams et al. 2017). However, the use of these approaches for determining the $K_{\mathrm{s}}$ have not yet been exploited, despite it may contribute for better defining the geometry of the wet bulbs, which represents one of the most influential variables for the design and management of drip irrigation systems (Arbat et al. 2013).

In this study, time-lapse ERI surveys were performed to identify the drying/wetting patters of the unsaturated soil profile following the application of deficit irrigation (DI) strategies integrated with drip irrigation systems. ERI surveys have provided important insights to describe the characteristics of the subsoil in terms of SWC, exploring the ER sensitivity at the different levels of SWC. Therefore, the aims of the study were (1) to identify and characterize the water flow paths occurring during micro-irrigation events, (2) to individuate the mechanisms of mass exchange in the subsoil (i.e., wetting and drying patterns) due to irrigation and plant transpiration $(T)$, and (3) to assess the potentiality of ERI for the soil water motion identification. The general objectives have been achieved by: (a) identifying ER distribution as function of the different SWC conditions during the irrigation season; (b) tracking and assessing the soil drying and wetting patterns through the ER changes during irrigation events supplied at different crop evapotranspiration $\left(\mathrm{ET}_{\mathrm{c}}\right)$ rates $\left(100,75\right.$ and $50 \%$ of $\left.\mathrm{ET}_{\mathrm{c}}\right)$; and (c) evaluating the potential use of ERI in determining $K_{\mathrm{s}}$ by assessing the temporal evolution of the wet bulbs under different irrigation scenarios (full and DI).

\section{Materials and methods}

\section{Irrigation setup and ancillary data}

The experimental trial was conducted in an orange orchard planted with 12-year-old trees (Citrus sinensis (L.) Osbeck) cv 'Tarocco Sciara' C1882 grafted on Carrizo citrange rootstock [Poncirus trifoliata (L.) Raf. $\times$ C. sinensis (L.) Osbeck], located in Southern Italy (Sicily) and managed by CREAOFA (Centro di Ricerca Olivicoltura, Frutticoltura e Agrumicoltura of the Italian Council for Agricultural Research and Agricultural Economics Analyses). This area presents semi-arid climate conditions, with mean air temperature and relative humidity values of $18.2{ }^{\circ} \mathrm{C}$ and $77 \%$, respectively; and annual rainfall and reference evapotranspiration $\left(\mathrm{ET}_{0}\right)$ values of 1300.7 and $656.6 \mathrm{~mm}$, respectively, for the year 2019. At the orchard under study, trees were trained with a rounded shape with plant density of 380 trees per hectare for $4 \times 6 \mathrm{~m}$ spacing. The effective rooting depth ranged between 30 and $40 \mathrm{~cm}$ (Cassiani et al. 2015; Vanella et al. 2018).

The effects of DI strategies on the soil drying/wetting patterns of the subsoil were compared with a control treatment (T1), which receives $100 \%$ of $\mathrm{ET}_{\mathrm{c}}$ by two surface drip lines, located directly close to the trunk, each characterized by a flow rate of $4 \mathrm{~L} \mathrm{~h}^{-1}$ per single-emitter (spaced $0.6 \mathrm{~m}$ on each drip line) with a total number of 12 emitters per tree $\left(48 \mathrm{~L} \mathrm{~h}^{-1}\right)$. The FAO-56 approach (Allen et al. 1998) was implemented for estimating the daily $\mathrm{ET}_{\mathrm{c}}$. Reference $\mathrm{ET}_{0}$, estimates using the Penman Monteith equation, was multiplied by the FAO- $56 K_{\mathrm{c}}$ for citrus adjusted by a localized coefficient (i.e., 0.7) calculated as ratio between the canopy cover size $\left(\mathrm{m}^{2}\right)$ and the area pertaining to each tree 
$\left(24 \mathrm{~m}^{2}\right.$ ) (Consoli et al. 2006, 2014, 2017; Fereres et al. 1981; Longo-Minnolo et al. 2020; Saitta et al. 2020). $\mathrm{ET}_{0}$ values were obtained using hourly and daily meteorological data provided by a weather station located $2 \mathrm{~km}$ far from the field site and managed by the Servizio Informativo Agrometeorologico Siciliano (SIAS).

The experimental design consists in a randomized block scheme with 4 irrigation treatments replicate in 3 times; each replica contains 24 trees (e.g., details are given in Consoli et al. 2014, 2017; Puglisi et al. 2019). The adopted DI strategies have the following characteristics:

- Sustained deficit irrigation (T2), receiving $75 \%$ of $\mathrm{ET}_{\mathrm{c}}$ by two dripper lines buried at $0.35 \mathrm{~m}$ from the soil surface, characterized by a flow rate of the single-emitter of 4 and $2 \mathrm{~L} \mathrm{~h}^{-1}$ (spaced $0.6 \mathrm{~m}$ on each drip line), emitting a total of $36 \mathrm{~L} \mathrm{~h}^{-1}$. This strategy allowed to neglect the evaporation losses (e.g., about 25\%, according to Consoli and Papa 2013), being the irrigation doses similar to those provided in $\mathrm{T} 1$;

- Regulated deficit irrigation (T3), receiving an irrigation amount of $100 \% \mathrm{ET}_{\mathrm{c}}$ until DOY (day-of-the-year) 217 in 2019 , and $50 \% \mathrm{ET}_{\mathrm{c}}$. from DOY 218 till the end of the of the irrigation season, emitting a total of 36 or $24 \mathrm{~L} \mathrm{~h}^{-1}$ per tree. The irrigation systems specifics are the same as in $\mathrm{T} 1$;

- Partial root-zone drying (T4), receiving $50 \%$ of $\mathrm{ET}_{\mathrm{c}}$ by two surface drip lines located $0.35 \mathrm{~m}$ from the trunk line, each characterized by a flow rate of the single-emitter of $4 \mathrm{~L} \mathrm{~h}^{-1}$ (spaced $0.6 \mathrm{~m}$ on each drip line); the drip lines are activated alternatively every week, thus wetting only half of the orange tree root system, emitting a total of 24 $\mathrm{L} \mathrm{h}^{-1}$ per tree.

The soil texture at the field site is sandy loam, with 65 , 12 and $23 \%$ of sand, clay and silt, respectively, and average bulk density of $1.25 \mathrm{~g} \mathrm{~cm}^{-3}$ (Aiello et al. 2014; D'Emilio et al 2018). SWC for field capacity (FC, log of the pressure in $\mathrm{hPa}, \mathrm{pF}=2$ ) and wilting point ( $\mathrm{WP}, \mathrm{pF}=4.2$ ) were determined using a sandbox and a pressure plate apparatus as described in Consoli et al. (2017). Ancillary data of SWC (Decagon, Inc., Pullman, WA, USA) and $T$ (Tranzflo NZ Ltd., Palmerston North, NZ) were used for monitoring at hourly scale the soil-water-plant exchanges processes occurring at each irrigation treatment (i.e., full and DI). In particular, $5 \mathrm{SWC}$ probes were installed at the field at $0.3 \mathrm{~m}$ below the soil surface, i.e., one for T1-T3 and 2 at both sides of T4 (West and East). Additionally, two trees per treatment (8 in total) were instrumented with a sap flow sensor, located at a height of $0.4 \mathrm{~m}$ on the tree trunks, adopting the heat pulse (HP) method and an hoc corrections for wounding effects were applied using 0.48 and 0.33 as fractions of wood and water in the sapwood, respectively (Saitta et al. 2020).
Details on sensors installed at the field site are reported in Mary et al. (2019), Vanella and Consoli (2018), and Vanella et al. $(2018,2019)$.

\section{Electrical resistivity imaging surveys}

\section{ERI data acquisition}

ERI surveys were carried out during the 2019 irrigation season (DOY, 168-278) using 2 ERI arrays, shown in Fig. 1a, b. The ERI arrays (with length of $10.65 \mathrm{~m}$ ) covered simultaneously two irrigation treatments (i.e., T1-T2 in Fig. 1a and T3-T4 in Fig. 1b). The ERI arrays consisted of 72 electrodes (stainless steel rods of about $0.15 \mathrm{~m}$, with diameter of $0.03 \mathrm{~m}$ ) buried for $2 / 3$ of their length into the soil surface with a spacing of $0.15 \mathrm{~m}$. ERI dataset were acquired by a ten-channel Syscal Pro resistivity meter (IRIS Instruments, Orleans, France). The electrode acquisition scheme was a full dipole-dipole skip-2 (with 5,000 direct and reciprocal measurements), because of its inherent strength in solving ER lateral changes (Samoüelian et al. 2005). The high spatial coverage of the adopted ERI configuration permitted to reach depths of investigation of about $1 \mathrm{~m}$ (Fig. 1).

The average time for each ERI dataset acquisition was about $25 \mathrm{~min}$ (Table 1). A pulse duration of $250 \mathrm{~ms}$ for each measurement cycle and a target of $50 \mathrm{mV}$ for potential readings were set as criteria for current injection. The

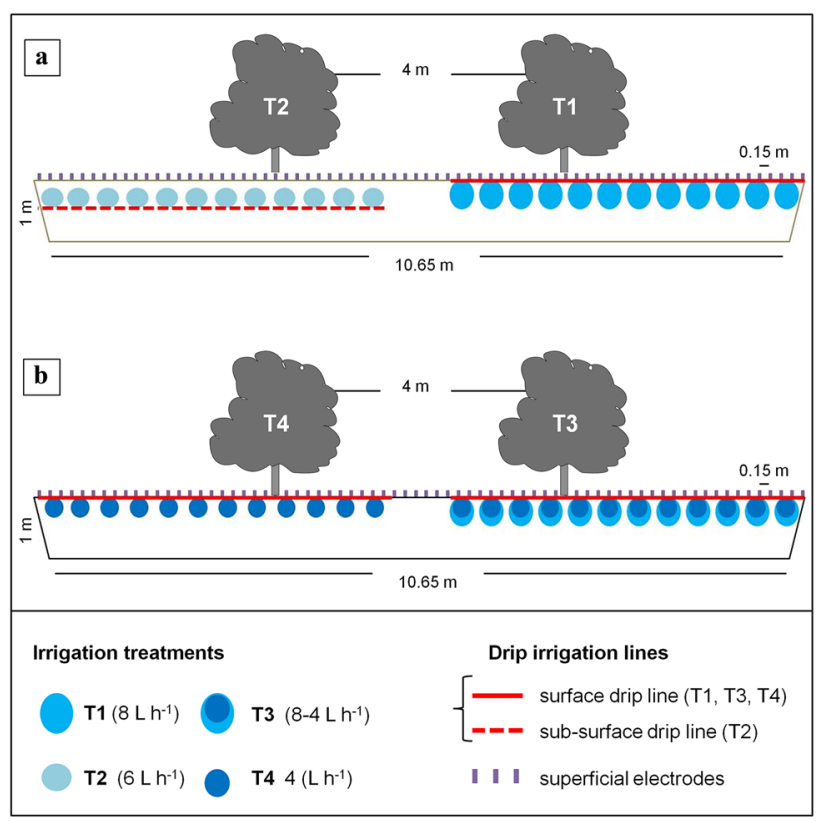

Fig. 1 Electrical resistivity imaging (ERI) arrays at the field site: a refers to acquisitions performed at T1 (full irrigation) and T2 (sustained deficit irrigation); and $\mathbf{b}$ at $\mathrm{T} 3$ (regulated deficit irrigation) and T4 (partial root-zone drying) 
Table 1 Time schedule of the seasonal and short-term electrical resistivity imaging (ERI) acquisitions carried out at the field site during irrigation timing $(t)$ for the different day-of-the-year (DOY): $t_{0}$, denotes the initial condition with no irrigation; $t_{1}-t_{5}$, refer to the irrigation phase and; $t_{6}-t_{7}$ refer to after the end of the irrigation

\begin{tabular}{|c|c|c|c|c|c|c|}
\hline \multirow[t]{2}{*}{ Irrigation season period (DOY) } & \multicolumn{2}{|c|}{ Irrigation timing $(t)$} & \multicolumn{2}{|l|}{$\mathrm{T} 1$ and $\mathrm{T} 2$} & \multicolumn{2}{|l|}{$\mathrm{T} 3$ and $\mathrm{T} 4$} \\
\hline & & & $\begin{array}{l}\text { Starting time } \\
\text { (hh:mm) }\end{array}$ & $\begin{array}{l}\text { Ending time } \\
\text { (hh:mm) }\end{array}$ & $\begin{array}{l}\text { Starting time } \\
\text { (hh:mm) }\end{array}$ & $\begin{array}{l}\text { End- } \\
\text { ing time } \\
\text { (hh:mm) }\end{array}$ \\
\hline \multirow[t]{8}{*}{ June (177-179) } & $t_{0}$ & No irrigation & 09:04 & $09: 33$ & $08: 47$ & 09:16 \\
\hline & $t_{1}$ & During irrigation & 09:04 & $10: 08$ & $09: 33$ & 10:01 \\
\hline & $t_{2}$ & & $10: 01$ & $10: 38$ & $10: 03$ & $10: 31$ \\
\hline & $t_{3}$ & & $10: 42$ & $11: 09$ & $10: 33$ & 11:01 \\
\hline & $t_{4}$ & & $11: 11$ & $11: 34$ & 11:06 & $11: 35$ \\
\hline & $t_{5}$ & & $11: 46$ & $12: 14$ & $11: 37$ & $12: 05$ \\
\hline & $t_{6}$ & After the end of the irrigation & $12: 02$ & $12: 48$ & $12: 11$ & $12: 39$ \\
\hline & $t_{7}$ & & $12: 51$ & $13: 19$ & $12: 41$ & 13:01 \\
\hline \multirow[t]{8}{*}{ July (198-200) } & $t_{0}$ & No irrigation & 09:06 & $09: 35$ & $08: 22$ & $08: 51$ \\
\hline & $t_{1}$ & During irrigation & $09: 38$ & 10:06 & $08: 58$ & $09: 27$ \\
\hline & $t_{2}$ & & 10:08 & $10: 36$ & $09: 28$ & 09:57 \\
\hline & $t_{3}$ & & $10: 38$ & 11:06 & 10:00 & $10: 29$ \\
\hline & $t_{4}$ & & 11:08 & $11: 35$ & $10: 32$ & 11:01 \\
\hline & $t_{5}$ & & $11: 38$ & $12: 05$ & 11:04 & $11: 33$ \\
\hline & $t_{6}$ & After the end of the irrigation & $12: 01$ & $12: 37$ & $11: 37$ & $12: 06$ \\
\hline & $t_{7}$ & & $12: 39$ & $13: 06$ & $12: 08$ & $12: 37$ \\
\hline \multirow[t]{8}{*}{ September (273-275) } & $t_{0}$ & No irrigation & 09:00 & 09:30 & $08: 40$ & 09:10 \\
\hline & $t_{1}$ & During irrigation & 09:34 & $10: 03$ & 09:18 & $09: 47$ \\
\hline & $t_{2}$ & & 10:05 & $10: 33$ & 09:48 & $10: 17$ \\
\hline & $t_{3}$ & & $10: 35$ & 11:03 & $10: 18$ & $10: 51$ \\
\hline & $t_{4}$ & & 11:06 & $11: 34$ & $10: 53$ & $11: 23$ \\
\hline & $t_{5}$ & & $11: 38$ & $12: 07$ & $11: 24$ & $12: 00$ \\
\hline & $t_{6}$ & After the end of the irrigation & $12: 12$ & $12: 40$ & $12: 02$ & $12: 31$ \\
\hline & $t_{7}$ & & $12: 42$ & $13: 01$ & $12: 33$ & $13: 02$ \\
\hline
\end{tabular}

Starting and ending times (hh:mm) are given in local time. T1-T4 refer to full irrigation, sustained deficit irrigation, regulated deficit irrigation and partial root-zone drying strategies, respectively

ERI monitoring was performed on different temporal scale: seasonal term and short term. The seasonal-term ERI monitoring allowed the evaluation of the background ER (i.e., at $t_{0}$, initial condition, no irrigation) during three periods of the irrigation season (June, July and September; Table 1). The short-term ERI monitoring was performed for assessing the temporal evolution of wet bulbs through the acquisition of ERI dataset, with high temporal resolution (time-lapse mode), specifically during $\left(t_{1}-t_{5}\right)$ and after $\left(t_{6}-t_{7}\right)$ the irrigation event. Details on ERI acquisitions duration and irrigation timing are reported in Table 1.

\section{ERI data processing}

ERI background and time-lapse dataset were processed with the freeware $R^{2}$ code (v3.1) (Binley 2016) to obtain forward/ inverse solution for two-dimensional (2D) current flow in a finite element mesh. As defined by Binley and Kemna (2005) and Binley (2015), the inverse solution is based on a regularized objective function combined with weighted least squares (an 'Occams' type solution). A 2D triangular mesh generated in Gmsh software (Geuzaine and Remacle 2009), consisting of 5,085 elements and 2,621 nodes, was adopted for the ERI background and time-lapse inversions. They were performed at 10 and 5\% error level, respectively (Vanella et al. 2018). The reconstruction of the 2D ERI imagery was performed using ParaView software (v3.8.1).

ER changes (in percentage terms, \%) were assessed by running the inversion of the ratio between the ERI dataset referred to selected time periods (e.g., $t_{1}, \ldots, t_{7}$, during and after irrigation, Table 1$)$ and the background ERI dataset $\left(t_{0}\right.$, Table 1), as follows: 
$d_{r}=\frac{d_{t}}{d_{0}} \cdot F\left(\sigma_{\mathrm{ohm}}\right)$,

where $d_{r}$ is the resistance ratio $(\Omega), d_{t}$ e $d_{0}(\Omega)$ are the resistance dataset of selected time periods $\left(t_{1}-t_{7}\right)$ and of the initial condition $\left(t_{0}\right)$, and $\mathrm{F}\left(\rho_{\text {ohm }}\right)$ is the resistance value $(\Omega)$ obtained by running the forward model for an arbitrarily chosen ER (i.e., $100 \Omega \mathrm{m}$ ).

This procedure allowed to identifying the ER changes (\%) compared to the initial condition ( $t_{0}$, no irrigation) and, thus, to evidence wetting or drying soil patterns (e.g., the threshold corresponding to a decline/increase in ER was set equal to or greater than 10\%). ER changes (\%) were mainly related to variations in SWC occurring in $\mathrm{T} 1-\mathrm{T} 4$, assuming that further variables including soil temperature, salinity, and composition and arrangement of soil particles, vary minimally during the ERI short-term monitoring (Samoüelian et al. 2005).

\section{Soil water motion rate measurements}

\section{ERI-based $K_{s}$ rates}

The soil water motion rate derived by ERI imagery $\left(K_{\mathrm{S} \text {, ERI }}\right)$ was calculated as the ratio between the maximum ERI-based wetting depth $\left(d_{\text {ERI }}\right)$ and the time between two consecutive instants within an irrigation event $\left(t_{1}-t_{5}\right.$, Table 1$)$, as follows:

$K_{s, \mathrm{ERI}}=\frac{\Delta d_{\mathrm{ERI}}}{\Delta t}$,

where, $\Delta d_{\mathrm{ERI}}(\mathrm{cm})$ is the difference between the maximum depths reached by the wet bulb at time $t_{i}$ and $t_{i-1}$, and $\Delta t$ (s) is the difference between $t_{i}$ and $t_{i-1}$ during the irrigation event $\left(t_{1}-t_{5}\right)$.

\section{Hydraulic conductivity at saturation measurements}

The falling head method (FH) was used to measure the soil saturated hydraulic conductivity $\left(K_{\mathrm{s}, \mathrm{FH}}\right)$ at the irrigation treatments (NAVFAC 1986). The $K_{\mathrm{s}, \mathrm{FH}}$ values were retrieved according to the procedure described by Caselles-Osorio and García (2006) and Pedescoll et al. (2009), consisting in the measurement of the travel time of a water column that moved vertically along an impervious permeameter driven into the soil.

The $K_{\mathrm{s}, \mathrm{FH}}$ apparatus was a steel tube with height equals to $0.65 \mathrm{~m}$ and an internal diameter of $0.10 \mathrm{~m}$. To supply a water pulse mode through the tube, a ball valve was connected with another $0.65 \mathrm{~m}$ polyethylene terephthalate tube with a capacity of $6.6 \mathrm{~L}$ (Fig. 2). At each treatment, the tube was placed at a distance of $0.5 \mathrm{~m}$ from the tree trunk,

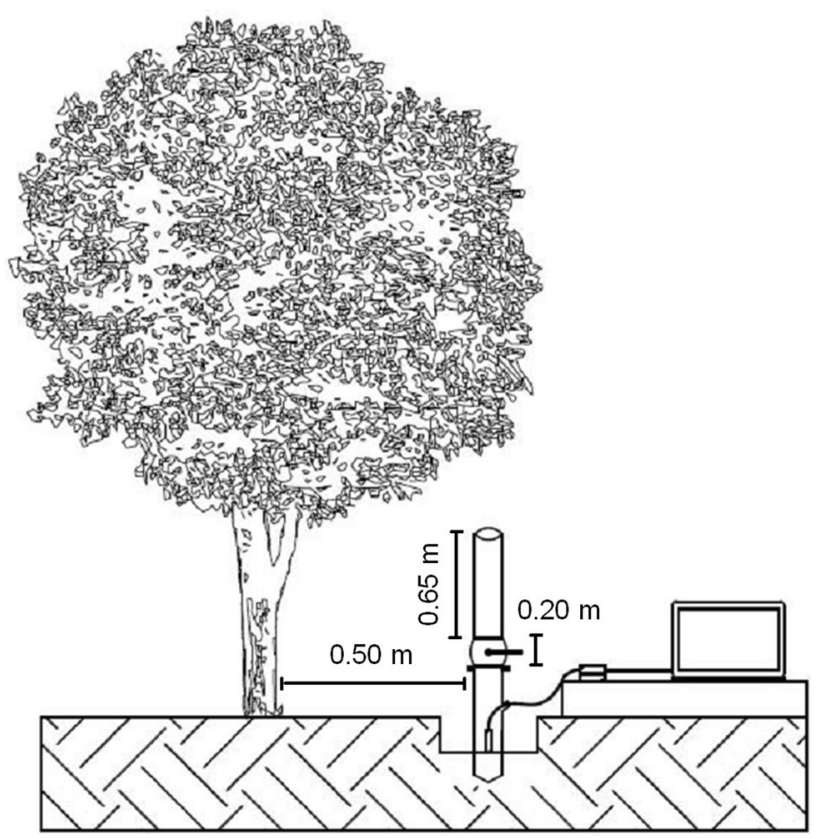

Fig. 2 Layout of the in situ saturated hydraulic conductivity measurements using the falling head procedure $\left(K_{\mathrm{s}, \mathrm{FH}}\right)$

in a hole pre-drilled into the soil surface ( $0.3 \mathrm{~m}$ depth); and then it was filled with water. A pressure probe (STS-Sensor Technik Sirnach, AG) was inserted inside the tube to measure the pressure (or water heights) variation in time during the soil water motion. The pressure probe worked through a data logger system (CR 200-R, Campbell Scientific), connected to a laptop, that recorded pressure data every minute up to the entire duration of each $K_{\mathrm{s}, \mathrm{FH}}$ measurement (set at $60 \mathrm{~min}$ ). A total of 5 repetitions per treatment unit (T1-T4) were collected during the 2019 irrigation season. Measurements of $K_{\mathrm{s}, \mathrm{FH}}$ were performed in the tree row adjacent to the one where ERI surveys were carried out.

The relationship between water level into the tube and time is represented by a negative exponential curve, and its slope is related to the $K_{\mathrm{s}, \mathrm{FH}}\left(\mathrm{m} \mathrm{s}^{-1}\right)$, as follows:

$K_{s, \mathrm{FH}}=\frac{d^{2} \ln (2 L / d)}{8 L t} \ln \frac{h_{1}}{h_{2}}$,

where, $d$ is the diameter of the tube (m); $L$ is the buried length of the tube (m); $t$ is time (s); $h_{1}$ and $h_{2}$ are the heights of the water level $(\mathrm{m})$ inside the tube at time 1 and time 2 (s), respectively.

To derive the $K_{\mathrm{s}, \mathrm{FH}}$ values, the best fit between the observed $\left(h_{\text {obs }}\right)$ and modeled $\left(\mathrm{h}_{\text {mod }}\right)$ heights of the water level was solved using the ordinary last square method, through an iterative non-linear procedure implemented in Excel solver (Frontline Systems, Incline Village, NV), following Eq. 4: 


$$
\sum_{t=0}^{n}\left(h_{\mathrm{obs}}(t)-h_{\text {mod }}(t)\right)^{2} \rightarrow 0
$$

where $h_{\text {obs }}(\mathrm{m})$ is the height of the water level observed inside the tube at time $t$ during the experiment; $h_{\text {mod }}(\mathrm{m})$ is the corresponding modeled water level calculated by inverting Eq. (3).

\section{Statistical analyses}

The goodness of the relationships between the mean SWC and ER decreasing (\%) observed at T1-T4, as well as those retrieved between the mean SWC and the ERI-derived-wet bulb depths, was identified on the basis of the coefficient of determination $\left(R^{2}\right)$. Discrepancies in $K_{\mathrm{s}}$ values among T1-T4 were assessed by performing one-way analyses of variance (ANOVA) (for both $K_{\mathrm{s}, \mathrm{ERI}}$ and $K_{\mathrm{s}, \mathrm{FH}}$ ) and the treatment mean values were compared each other adopting the Fisher's least significant difference test (LSD) at 0.05 significance level $(p \leq 0.05)$.

\section{Results}

\section{General weather patterns, transpiration, irrigation and SWC}

During the 2019 irrigation season, the cumulative $\mathrm{ET}_{0}$ and rainfall values were 643 and $91 \mathrm{~mm}$, respectively (Fig. 3a, c); whereas, the cumulative irrigation amounts were 317 , 238, 237 and $159 \mathrm{~mm}$ for T1, T2, T3 and T4, respectively. The daily $\mathrm{ET}_{0}$ and $\mathrm{ET}_{\mathrm{c}}$ values observed during the seasonal ERI campaigns in June, July and September, 2019 (Table 1) were 6.79, 6.51, and $3.83 \mathrm{~mm} \mathrm{day}^{-1}$ and 3.32 , 3.18 and $1.87 \mathrm{~mm} \mathrm{day}^{-1}$, respectively (Fig. 3a). As for daily $\mathrm{ET}_{0}$ and $\mathrm{ET}_{\mathrm{c}}$, a similar decreasing temporal trend throughout the 2019 irrigation season was observed in terms of daily $T$ rates (Fig. 3b). At the irrigation treatment level, daily $T$ rates shown average values of $1.55( \pm 0.19), 1.10( \pm 0.18), 0.86$ $( \pm 0.12)$ and $1.18( \pm 0.18) \mathrm{mm} \mathrm{day}^{-1}$ in T1, T2, T3 and T4, respectively.

In general, the SWC conditions during the irrigation period ranged between the FC $\left(0.28 \mathrm{~m}^{3} \mathrm{~m}^{-3}\right)$ and the WP $\left(0.14 \mathrm{~m}^{3} \mathrm{~m}^{-3}\right)$ values for the soil under study (showing a water-holding capacity of $0.14 \mathrm{~m}^{3} \mathrm{~m}^{-3}$ ) (Fig. 3c). During the seasonal ERI campaigns, hourly SWC values at the initial condition $\left(t_{0}\right)$, ranged from 0.17 to $0.25 \mathrm{~m}^{3} \mathrm{~m}^{-3}$ in June, from 0.21 to $0.25 \mathrm{~m}^{3} \mathrm{~m}^{-3}$ in July, and from 0.20 to $0.25 \mathrm{~m}^{3} \mathrm{~m}^{-3}$ in September, showing SWC higher in T1 and T2 $(0.24 \pm 0.01$ $\left.\mathrm{m}^{3} \mathrm{~m}^{-3}\right)$ than that in T3 and T4 $\left(0.20 \pm 0.02 \mathrm{~m}^{3} \mathrm{~m}^{-3}\right)$.

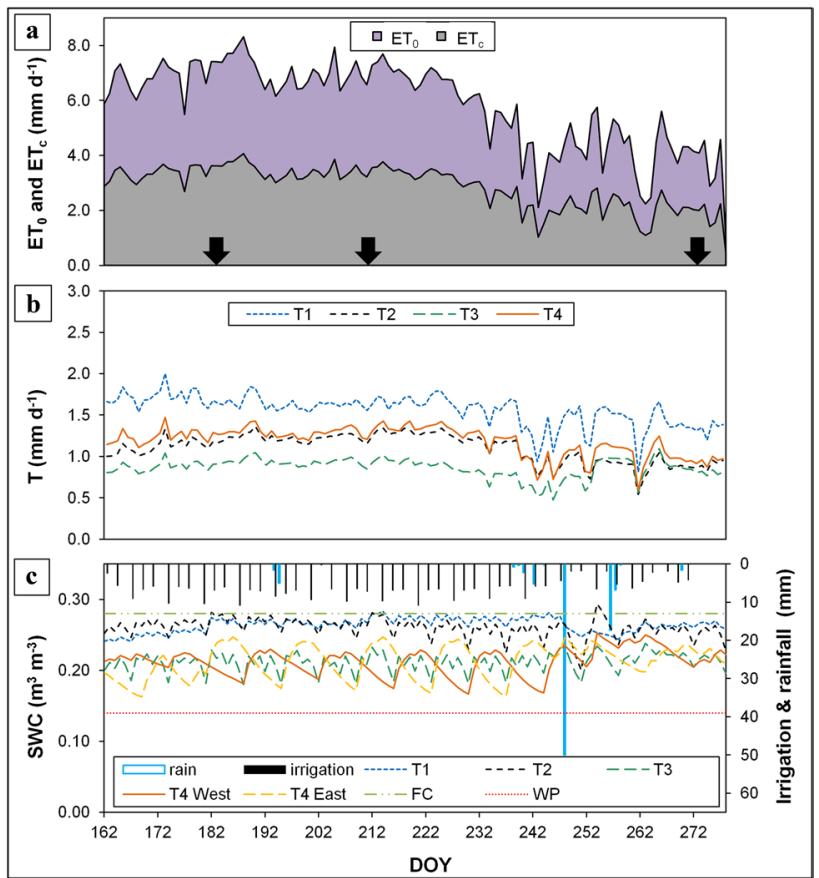

Fig. 3 Daily temporal patterns of a reference $\left(\mathrm{ET}_{0}\right)$ and crop $\left(\mathrm{ET}_{\mathrm{c}}\right)$ evapotranspiration rates $\left(\mathrm{mm} \mathrm{day}^{-1}\right)$; b transpiration $(T)\left(\mathrm{mm} \mathrm{day}^{-1}\right)$, and $\mathbf{c}$ soil water content (SWC) conditions $\left(\mathrm{m}^{3} \mathrm{~m}^{-3}\right)$, irrigation and rainfall $(\mathrm{mm})$ at the field site from day-of-the-year (DOY) 162-278 (2019). The arrows indicates the periods of the seasonal electrical resistivity imaging (ERI) monitoring. T1-T4 refer to full irrigation, sustained deficit irrigation, regulated deficit irrigation and partial root-zone drying strategies, respectively; FC and WP stand for field capacity and wilting point, respectively

\section{Background ERI images}

Figure 4 shows the background ER tomograms at the initial condition ( $t_{0}$, i.e., no irrigation) in T1-T4, within the seasonal-term ERI monitoring (Table 1).

Mean ER values $(\Omega \mathrm{m})$ showed a decreasing trend of about $16 \%$ at all the treatments from the beginning (June) to the end (September) of the 2019 irrigation season (Fig. 5a-d). This ER decreasing pattern was higher in T1 (Fig. 5a) and T2 (Fig. 5b) (19\% and 20\%, respectively) and lower in T3 (Fig. 5c) and T4 (Fig. 5d) (10\% and 14\%, respectively).

\section{Time-lapse monitoring by ERI}

Figures 6, 7 and 8 show the time-lapse inversions of the short-term ERI dataset acquired during $\left(t_{1}-t_{5}\right)$ and after $\left(t_{6}-t_{7}\right)$ the irrigation events, compared to the initial condition $\left(t_{0}\right.$, Fig. 4). The mean ER changes (\%) observed in T1-T4 during the short-term ERI campaigns are reported in Fig. 9. 


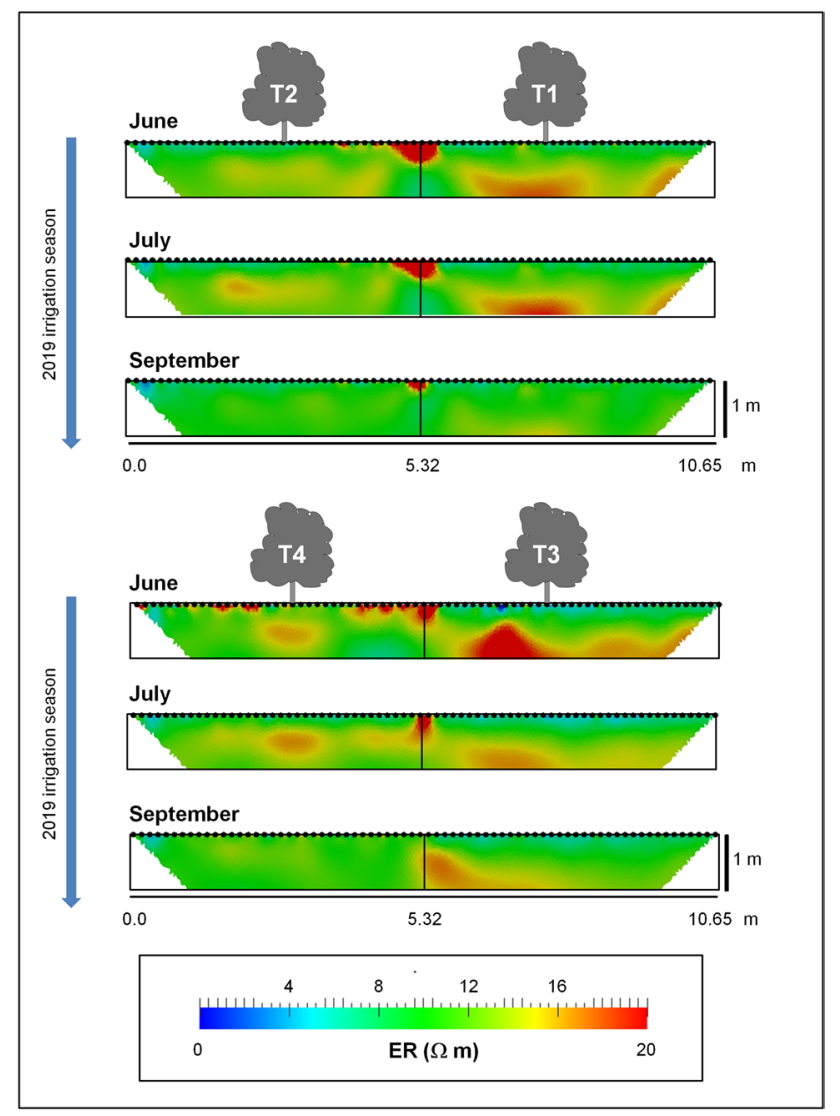

Fig. 4 Background electrical resistivity (ER) tomograms at T1-T4 (values are in $\Omega \mathrm{m}$ ) for the field surveys (June, July and September, 2019). T1-T4 refer to full irrigation, sustained deficit irrigation, regulated deficit irrigation and partial root-zone drying strategies, respectively

Evident contrasts in ER changes (\%) became readily apparent for the different irrigation events during the 2019 irrigation season, representing ER increasing (yellow areas) and decreasing (blue areas) patterns. The ER increasing pattern was detected mainly in the deeper soil layers of T4 in June (Figs. 6, 9d), reaching ER increases of about $20 \%$ and involving in average $28 \%$ of the entire ERI transect. However, the ER decreasing trends represent the most predominant phenomenon, acting especially in the shallow soil layers due to irrigation (Figs. 6, 7, 8, 9 ). Generally, irrigation resulted in the formation of individual rounded wet bulbs that became elliptical with time and formed a continuous "wet band" by their overlapping. However, the shape of the wet bulbs identified by ERI (Figs. $6,7,8)$ was dependent on the background SWC $\left(t_{0}\right)$ in T1-T4, and on the different flow rates emitted (i.e., $8 \mathrm{~L}$ $\mathrm{h}^{-1}$ in $\mathrm{T} 1 ; 6 \mathrm{~L} \mathrm{~h}^{-1}$ in T2; $8 \mathrm{~L} \mathrm{~h}^{-1}$ in T3 until DOY 217 and then $4 \mathrm{~L} \mathrm{~h}^{-1}, 4 \mathrm{~L} \mathrm{~h}^{-1}$ for $\mathrm{T} 4$ ).
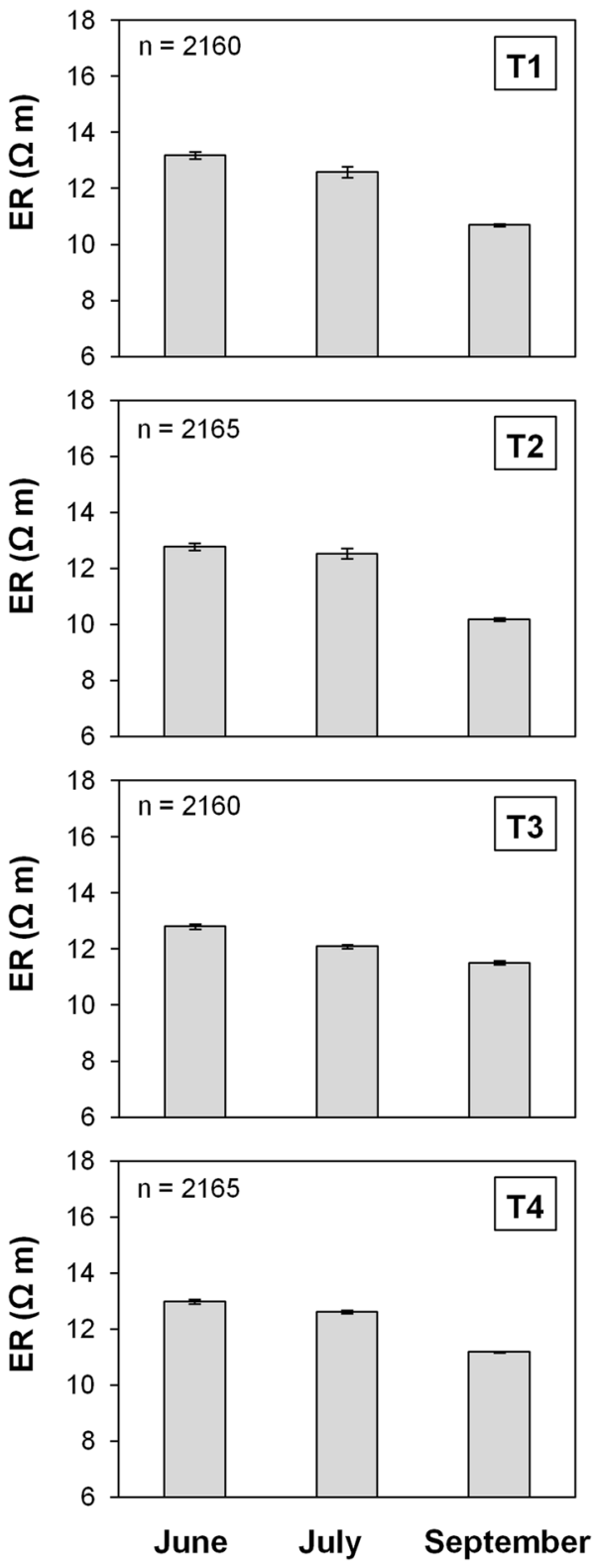

Fig. 5 Mean values (and standard error) of electrical resistivity (ER) tomograms $(\Omega \mathrm{m})$ at background $\left(t_{0}\right)$ for T1 (full irrigation), T2 (sustained deficit irrigation), T3 (regulated deficit irrigation) and T4 (partial root-zone drying); $\mathrm{n}$ corresponds to the number of cells of each tomogram

\section{SWC-wet bulbs relationship}

Figure $10 \mathrm{a}, \mathrm{b}$ shows that wet bulbs were identified better when the initial SWC was lower, i.e., in T3 and T4; whereas, their identification was less clear during wetter initial conditions (as in $\mathrm{T} 1$ and $\mathrm{T} 2$ ). This behavior was also observed when comparing the decreasing patterns during the seasonal ERI monitoring, being the degree of definition of these decreases less detectable from June to September, 2019. Specifically, a good relationship was 


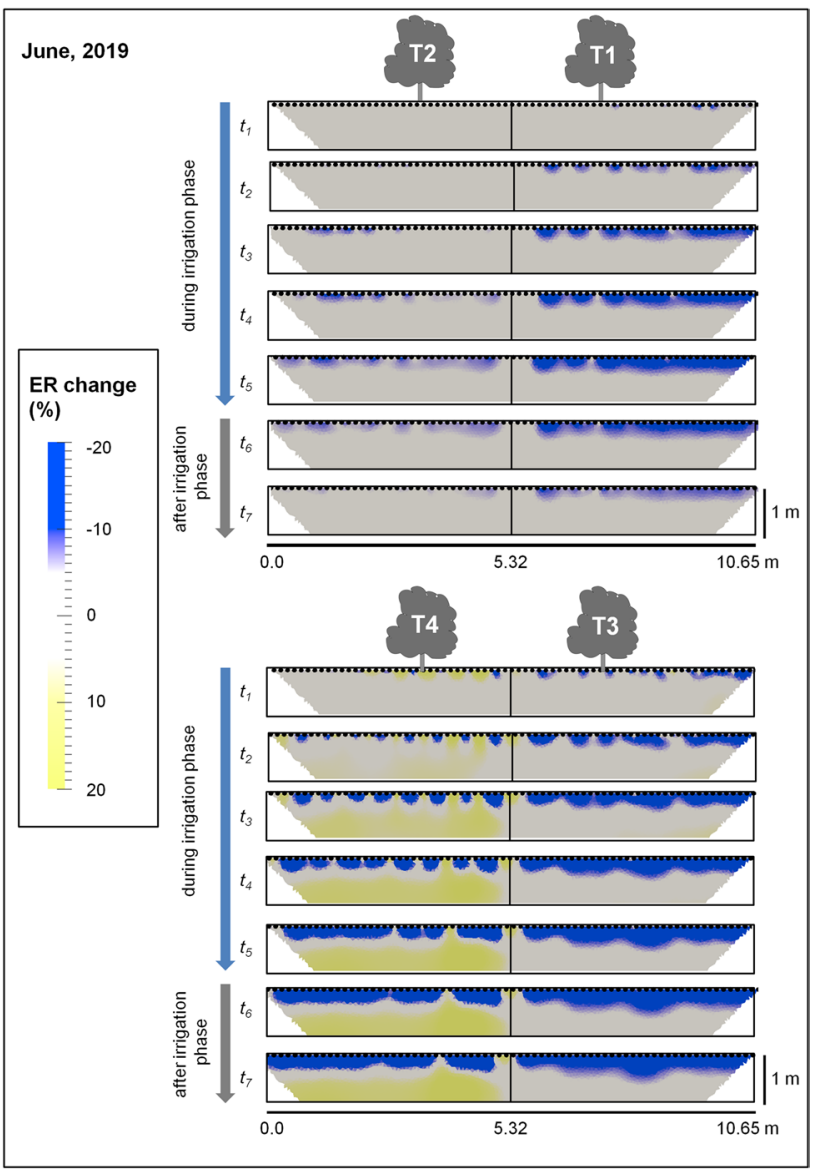

Fig. 6 Electrical resistivity (ER) change (\%) observed during the irrigation phases and after the irrigation event $\left(t_{1}-t_{7}\right)$ compared to the initial condition $\left(t_{0}\right)$ in June, 2019. T1-T4 refer to full irrigation, sustained deficit irrigation, regulated deficit irrigation and partial rootzone drying strategies, respectively

observed between the mean hourly SWC measured during the ERI acquisitions and the observed average ER \% decrease, with $R^{2}$ of 0.79 (Fig. 10a). A good relationship was also observed between the mean hourly SWC and the ERI-derived maximum depth of the wet bulbs with $R^{2}$ of 0.82 (Fig. 10b).

\section{Emitting rates-wet bulbs relationship}

The increasing of the emitter flow rate raised the horizontal radius of the wet bulbs (T1-T3 versus T4). In fact, when the same flow rate was supplied in $\mathrm{T} 1$ and $\mathrm{T} 3$ (i.e., 8 $\mathrm{L} \mathrm{h}^{-1}$ ), the horizontal radius was similar in June and July, reaching nearly half of the distance between the emitters (i.e., $0.6 \mathrm{~m}$ ) at time $t_{2}$ (Figs. 6, 7). Such treatments were, thus, characterized by a continuous horizontal band of SWC along the irrigation lines. On September, when T3 was supplied as T4 $\left(4 \mathrm{~L} \mathrm{~h}^{-1}\right)$, the wetting fronts of T3-T4 showed smaller horizontal radius (Fig. 8).

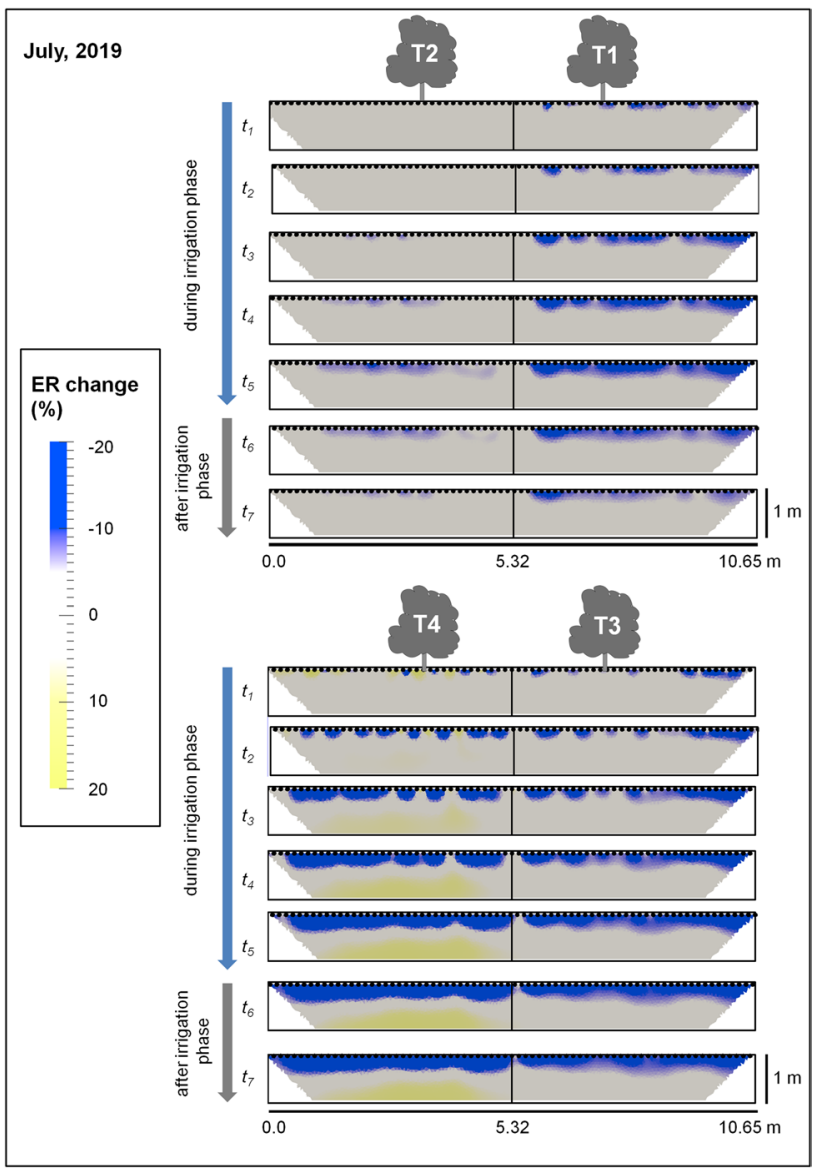

Fig. 7 Electrical resistivity (ER) change (\%) observed during the irrigation phases and after the irrigation event $\left(t_{1}-t_{7}\right)$ compared to the initial condition $\left(t_{0}\right)$ in July, 2019. T1-T4 refer to full irrigation, sustained deficit irrigation, regulated deficit irrigation and partial rootzone drying strategies, respectively

On the other hand, increasing the emitter flow rate did not raise the vertical radius of the wet bulbs. In fact, it was quite similar and oscillating around $0.3 \mathrm{~m}$ depth from the soil surface in T1, T3 and T4. After the time $t_{3}$, a prevalent lateral water movement was observed in the irrigation treatments. A stationary pattern was observed at the end of irrigation events $\left(t_{6}-t_{7}\right)$, with a decline of magnitude of ER decreasing in average 5\% less negative than in $t_{5}$ (Fig. 9). No vertical preferential flow patterns were detected.

\section{Hydraulic conductivity at saturation results}

Figure 11 shows the mean ( \pm standard error) $K_{\mathrm{S}}$ values $\left(\mu \mathrm{m} \mathrm{s}^{-1}\right)$ obtained from ERI $\left(K_{\mathrm{s}, \mathrm{ERI}}\right)$ and FH $\left(K_{\mathrm{s}, \mathrm{FH}}\right)$ approaches. In Fig. 11a, it is inferred that T2 had the lowest $K_{\text {s.ERI }}$ value $\left(6.43 \mu \mathrm{m} \mathrm{s}^{-1}\right)$ showing significant differences with T1 $\left(25.03 \mu \mathrm{m} \mathrm{s}^{-1}\right)$. The highest $K_{\mathrm{s}, \text { ERI }}$ values were found in the surface DI treatments (T3-T4) with mean $K_{\mathrm{s}, \mathrm{ERI}}$ 


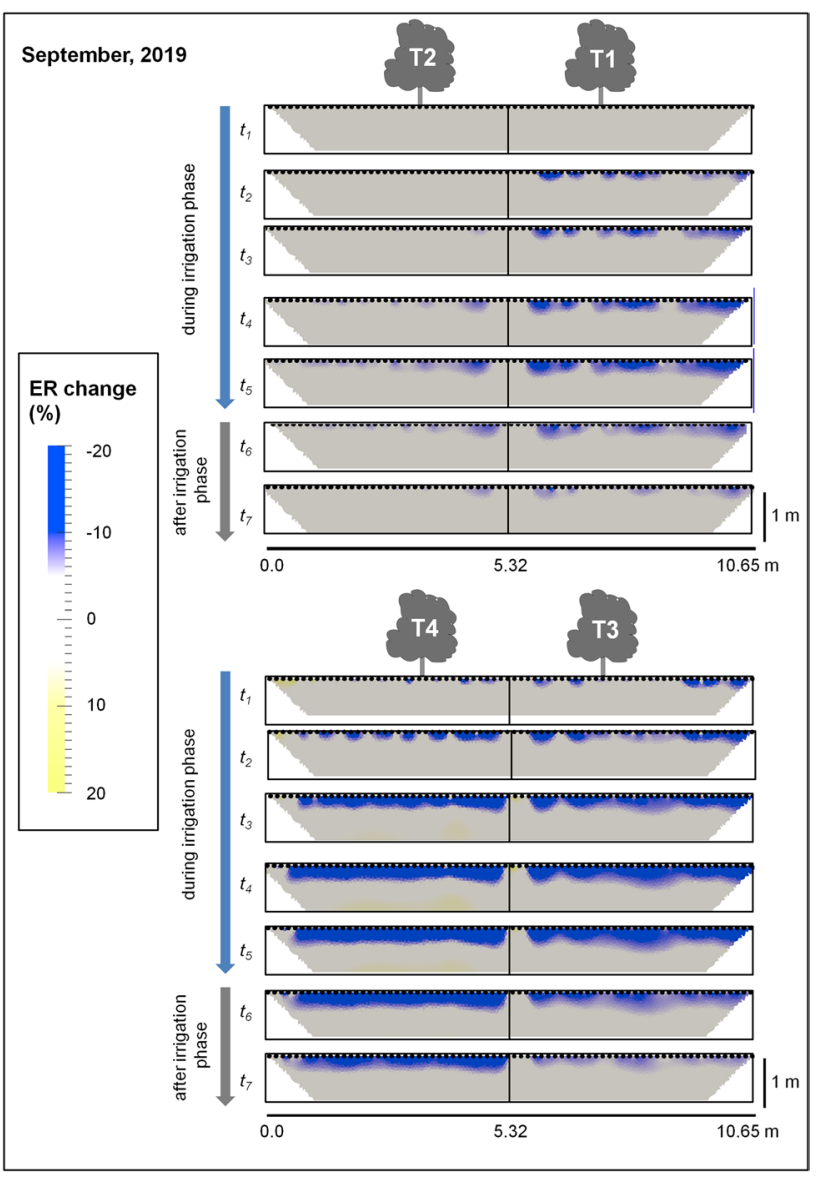

Fig. 8 Electrical resistivity (ER) change (\%) observed during the irrigation phases and after the irrigation event $\left(t_{1}-t_{7}\right)$ compared to the initial condition $\left(t_{0}\right)$ in September, 2019. T1-T4 refer to full irrigation, sustained deficit irrigation, regulated deficit irrigation and partial root-zone drying strategies, respectively

values of $36.33 \mu \mathrm{m} \mathrm{s}^{-1}$, not showing significant differences among them.

Different patterns were observed for $K_{\mathrm{s}, \mathrm{FH}}$ values (Fig. 11b). Significant differences were found between T4 and T2-T3, with $K_{\mathrm{s}, \mathrm{FH}}$ values of $194.23 \mu \mathrm{m} \mathrm{s}^{-1}$ and $140.38-132.96 \mu \mathrm{m} \mathrm{s}^{-1}$, respectively. Contrarily, no significant differences were observed between T1 $\left(177.22 \mu \mathrm{m} \mathrm{s}^{-1}\right)$ and the other treatments.

Nevertheless, the magnitudes of $K_{\mathrm{s}, \mathrm{ERI}}$ and $K_{\mathrm{s}, \mathrm{FH}}$ were quite different, presenting the $\mathrm{FH}$ measurements one order of magnitude higher than the ERI approach.

\section{Discussion}

In this study, the ERI technique was applied to identify the drying/wetting patters of the unsaturated soil profile following the application of DI strategies integrated with drip irrigation systems. The 2D ERI surveys provided important
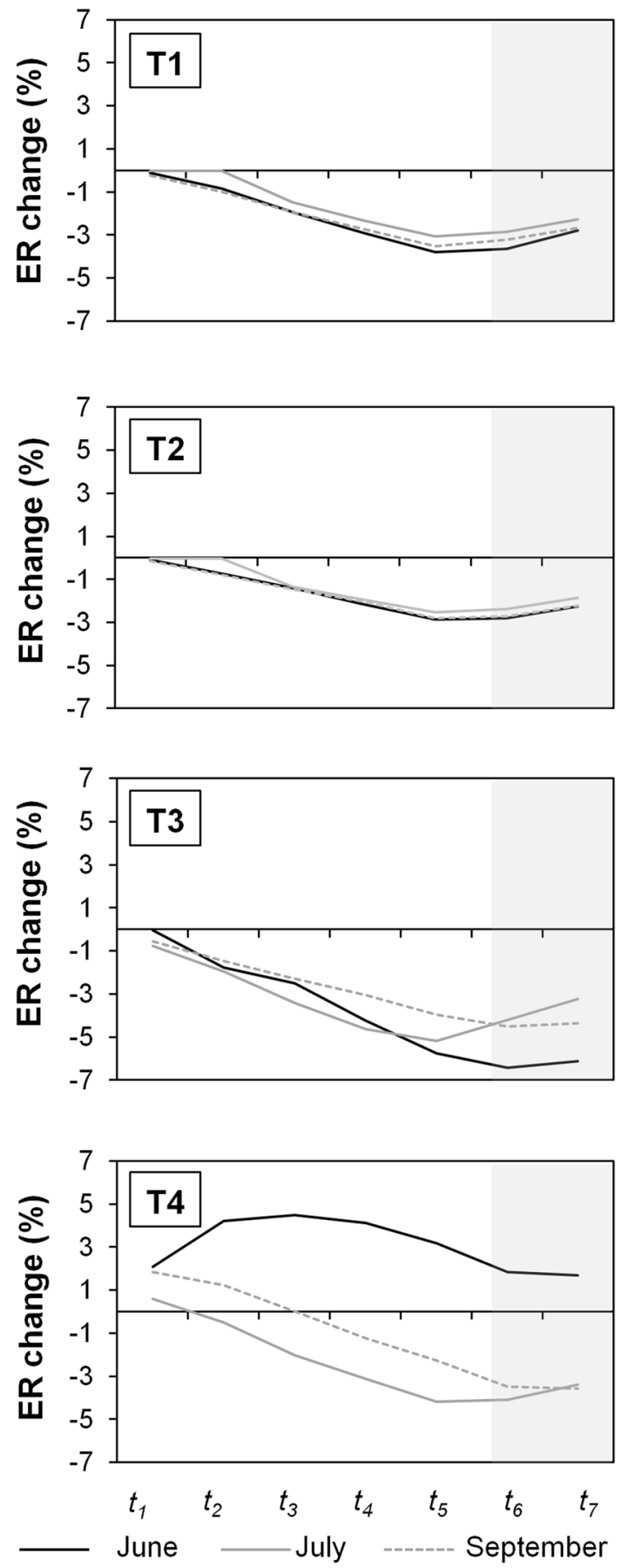

Fig. 9 Mean electrical resistivity (ER) change (\%) observed during the irrigation phases $\left(t_{1}-t_{5}\right)$ and after the irrigation event (shaded area; $\left.t_{6}-t_{7}\right)$ in comparison to the initial condition ( $t_{0}$, no irrigation period) for the ERI monitoring period (June, July and September, 2019). T1-T4 refer to full irrigation, sustained deficit irrigation, regulated deficit irrigation and partial root-zone drying strategies, respectively

insights to describe the characteristics of the subsoil in terms of SWC, exploring the ER sensitivity at the different levels of SWC; this aspect has been scarcely investigated in 

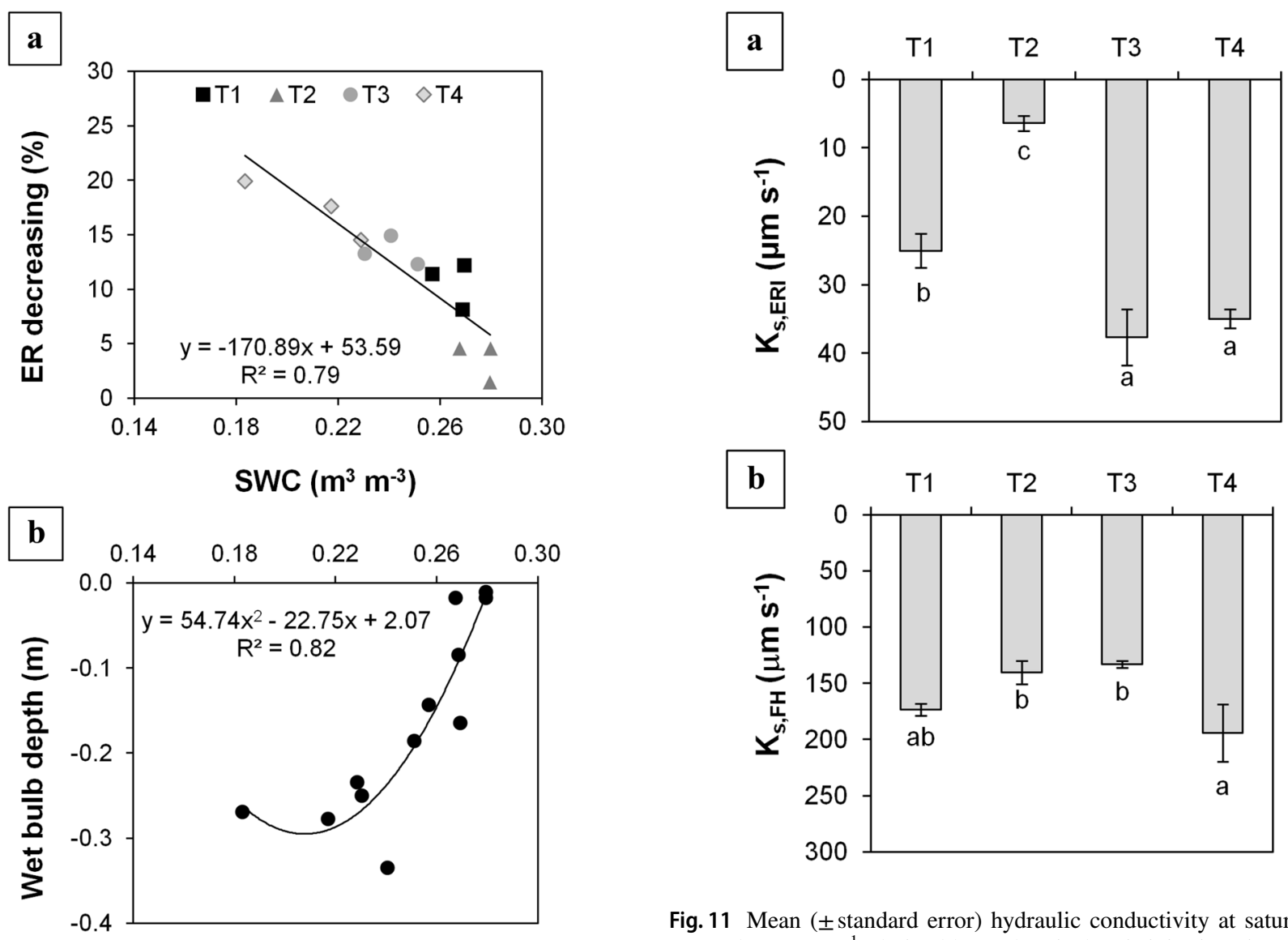

Fig. 11 Mean ( \pm standard error) hydraulic conductivity at saturation $\left(K_{\mathrm{s}}\right)$ values $\left(\mu \mathrm{m} \mathrm{s}^{-1}\right)$ derived by a electrical resistivity imaging (ERI) $\left(K_{\mathrm{s}, \mathrm{ERI}}\right)$; and b falling head $(\mathrm{FH})$ method $\left(K_{\mathrm{s}, \mathrm{FH}}\right)$. T1-T4 refer to full irrigation, sustained deficit irrigation, regulated deficit irrigation and partial root-zone drying strategies, respectively. Different letters indicate $K_{\mathrm{s}}$ significant differences among treatments according to Fisher's least significant difference test (LSD) $(p \leq 0.05)$ refer to full irrigation, sustained deficit irrigation, regulated deficit irrigation and partial root-zone drying strategies, respectively

previous studies (Mary et al. 2019). In fact, following the homogeneous structure of the soil and the climatic conditions at the field site (Fig. 3), it was shown that the driving factor explaining the decreasing trend in ER is closely related to SWC changes induced by drip irrigation. This consideration is confirmed by independent SWC measurements that showed a transition pattern from drier soil conditions (higher ER values) to wetter conditions (lower ER values), going from June to September during the 2019 irrigation season. It was also confirmed, comparing the seasonal ERI images, that those treatments that received more water (T1 and T2) showed lower ER values than those subjected to more severe DI strategies (T3 and T4) (Figs. 3, 4). This observation is in line with the results of Cassiani et al. (2015) and Bertermann and Schwarz (2018), which have achieved robust relationships between the ER and the different levels of SWC at the laboratory scale, recognizing the SWC as the most influential soil property. This points out the need of using ancillary data for characterizing the field

condition for a realistic interpretation of ERI data (Vanella et al. 2019).

The SWC deficit, detected by the increase in ER that occurs in the deeper soil layers of T4 especially in June, was attributed to the combination of higher $T$ rates (Fig. 3b) and lower SWC (Fig. 3c) recorded in this treatment in comparison with the other DI treatments. This ER increasing pattern (up to 20\%) was not observed in the other DI treatments, since they received more irrigation and, therefore, root-water uptake (RWU) process was partially masked by the higher initial SWC conditions. Similar observations were obtained by other authors (Mares et al. 2016; Mary et al. 2019; Vanella et al. 2018), who detected a strictly alignment between the high $\mathrm{T}$ rates derived by sap flow measurements and the decline of SWC retrieved by ERI due to the RWU. However, uncertainties in the estimation of $T$ rates cannot be excluded and need to be addressed (Flo et al. 2019; Motisi et al. 2012). In this regard, a meta-analysis carried out by Flo et al. (2019), using data of 16 studies and 21 species, evidenced that the average accuracy deviation for sap flow 
HP method was about 14\%. Probes installation, wounding, scaling sap flow variability and variation in wood parameters were highlighted as the main uncertainties sources influencing sap flow HP method accuracies (Flo et al. 2019; Intrigliolo and Castel 2007; Intrigliolo et al. 2009; Motisi et al. 2012). On the other hand, ER decreasing patterns obtained by the short-term ERI analysis allowed delineating the wet bulbs in different irrigation scenarios (full irrigation versus DI). Small differences were observed between the vertical extent of the wet bulbs formed as a result of the different flow rates $\left(8-4 \mathrm{~L} \mathrm{~h}^{-1}\right)$, reaching average depths ranging from 0.16 to $0.46 \mathrm{~m}$ from the soil surface. This confirmed that the vertical flow component depends mainly on the soil texture (i.e., sandy loam). On the contrary, increasing the flow rate from 4 to $8 \mathrm{~L} \mathrm{~h}^{-1}$ had a more evident influence on the horizontal component, raising the horizontal radius of the wet bulbs. These findings were in agreement with those reached by Elaiuy et al. (2015), who suggested the use of a wider spacing among drippers when the emitting rates increased from 1.0 to $1.6 \mathrm{~L} \mathrm{~h}^{-1}$. Moreover, the absence of preferential vertical flow detected by ERI demonstrates the efficiency of the microrrigation system and the appropriate irrigation scheduling operating at the field (i.e., no percolation flow means that the whole SWC is available for the RWU). In this scenario, ERI may be considered as a valid tool for evaluating the irrigation system emission uniformity, aiming at monitoring the discharged flow rates of several drippers at the same time (Rossi et al. 2013). Furthermore, the study demonstrates the ability of ERI to detect wet bulbs for SWC between 0.18 and $0.27 \mathrm{~m}^{3} \mathrm{~m}^{-3}$, providing useful information on the DI regime. For example, the SWC observed in T2 did not allow identifying well-defined wet bulbs due to the high initial SWC.

The approaches applied to determine $K_{\mathrm{s}}$ in the different irrigation scenarios $\left(K_{\mathrm{s}, \mathrm{ERI}}\right.$ and $\left.K_{\mathrm{s}, \mathrm{FH}}\right)$ have revealed different patterns, which also vary in their magnitude, mainly due to the different measurement scales and methodologies adopted. More specifically, $K_{\mathrm{s}, \mathrm{ERI}}$ presented significantly lower values for those treatments with higher SWC (T1 and T2 vs T3 and T4; Fig. 11), whereas no significant differences were observed in $K_{\mathrm{s}, \mathrm{FH}}$. This could be due to the $\mathrm{FH}$ method that started measuring from $30 \mathrm{~cm}$ above the soil surface, thus neglecting the upper layer where, as identified by the ERI technique, most of the SWC is present, unifying the effect of the irrigation strategies on $K_{\mathrm{s}, \mathrm{FH}}$. Thus, the soil sampled with FH may not satisfied the saturated conditions at the base of the HF method, which could explain the higher order of magnitude of $K_{\mathrm{s}, \mathrm{FH}}$ compared to $K_{\mathrm{s}, \mathrm{ERI}}$. Additionally, $K_{\mathrm{s}, \mathrm{ERI}}$ (Eq. 2) performance mainly depends on the ability of ERI in detecting the wet bulbs which in this study seems to be strictly influenced by the degree of soil saturation. Otherwise, FH approach determines $K_{\mathrm{s}, \mathrm{FH}}$ from the difference of water heights in the permeameter with time, which can be the result not only of a prevalent vertical flow but also of a horizontal one. Even if no preferential vertical flow were individuated by ERI, it is not possible to exclude the presence of preferential horizontally flow due to the roots distribution in T1-T4, that could explain the higher order of magnitude of $K_{\mathrm{s}, \mathrm{FH}}$ values compared to $K_{\mathrm{s}, \mathrm{ERI}}$. Several authors have related the higher infiltration capacity of irrigated soils to the formation of macro-pores due to roots activity, which can contribute almost $85 \%$ of the total infiltration variation (Bronick and Lal 2005; Cameira et al. 2003; Wu et al. 2017). However, some authors have pointed out some limitations in the in situ $K_{\mathrm{s}}$ determination, as the necessity of a high number of measurements in order to accurately characterize and represent the wide $K_{\mathrm{s}}$ variability in space and time (Zhang et al. 2019). In particular, $K_{\mathrm{s}, \mathrm{FH}}$ estimates depend on the initial SWC, on the height of the water released in the soil and on the duration of the soil water motion process (Alagna et al. 2016). Furthermore, the FH methodology provides point-based $K_{\mathrm{s}}$ estimations that may not be representative of the entire system, which is partially solved with the use of the ERI technique. However, despite the limitations above-mentioned, the results of this study indicate the potential use of the FH methodology to evaluate the $K_{\mathrm{s}}$ on the least disturbed layers of the soil (depth $>0.3 \mathrm{~m}$ ) while the ERI surveys proved to be more useful to determine the effect of irrigation treatments on $K_{\mathrm{s}}$ estimates in unsaturated soils.

\section{Conclusion}

The study herein presented highlighted that hydrogeophysical techniques can play an important role in supporting irrigation management strategies for giving insights on the efficiency of the irrigation systems as well as for characterizing the soil water dynamics.

On the one hand, ERI has permitted to identify the water flow paths under different drip irrigation scenarios by delineating the wet soil bulbs. The resulting ERI-derived wet soil bulbs have reached similar depths in all irrigation treatments, regardless of flow rates, suggesting that the vertical component of the flow is prevalent and depends mainly on the soil structure. In addition, ERI technique has allowed to evaluate the efficiency of the microirrigation through the simultaneous monitoring of the flow supplied by the different drippers, enabling the identification of potential failures in the irrigation system. Furthermore, the absence of preferential vertical flows detected by ERI indicates that the irrigation schedule is appropriate. On the other hand, the identification of subsoil ER patterns has permitted to capture the soil drying effect related to the RWU process, especially in the irrigation strategy characterized by the most severe deficit. Finally, ERI resulted more useful for determining the $K_{\mathrm{s}}$ in 
unsaturated soils than FH methodology, which provided $K_{\mathrm{s}}$ information mainly referable to the less disturbed soil layers.

Acknowledgements The authors wish to thank Servizio Informativo Agrometeorologico Siciliano (SIAS) for weather data and the personnel of Centro di Ricerca Olivicoltura, Frutticoltura e Agrumicoltura of the Italian Council for Agricultural Research and Agricultural Economics Analyses (CREA-OFA, Acireale) for their hospitality at the field site. The work was carried out in the frame of the PON Attraction and International Mobility (AIM) 1848200-2 initiative (D.V.).

Funding Open access funding provided by Università degli Studi di Catania within the CRUI-CARE Agreement.

\section{Compliance with ethical standards}

Conflict of interest On behalf of all authors, the corresponding author states that there is no conflict of interest.

Open Access This article is licensed under a Creative Commons Attribution 4.0 International License, which permits use, sharing, adaptation, distribution and reproduction in any medium or format, as long as you give appropriate credit to the original author(s) and the source, provide a link to the Creative Commons licence, and indicate if changes were made. The images or other third party material in this article are included in the article's Creative Commons licence, unless indicated otherwise in a credit line to the material. If material is not included in the article's Creative Commons licence and your intended use is not permitted by statutory regulation or exceeds the permitted use, you will need to obtain permission directly from the copyright holder. To view a copy of this licence, visit http://creativecommons.org/licenses/by/4.0/.

\section{References}

Aiello R, Bagarello V, Barbagallo S, Consoli S, Di Prima S, Giordano G, Iovino M (2014) An assessment of the Beerkan method for determining the hydraulic properties of a sandy loam soil. Geoderma 235:300-307

Alagna V, Bagarello V, Di Prima S, Giordano G, Iovino M (2016) Testing infiltration run effects on the estimated water transmission properties of a sandy-loam soil. Geoderma 267:24-33

Allen RG, Pereira LS, Raes D, Smith M (1998) Crop evapotranspiration: guidelines for computing crop requirements. Irrigation and Drainage Paper No. 56, FAO, Rome, Italy, 300(9), D05109

Arbat G, Puig-Bargués J, Duran-Ros M, Barragán J, De Cartagena FR (2013) Drip-irriwater: computer software to simulate soil wetting patterns under surface drip irrigation. Comput Electron Agric 98:183-192

Bertermann D, Schwarz H (2018) Bulk density and water contentdependent electrical resistivity analyses of different soil classes on a laboratory scale. Environ Earth Sci 77(16):570

Binley A (2016) R2 version 3.1 Lancaster University website: http:// www.es.lancs.ac.uk/people/amb/Freeware/R2/R2.htm. Accessed 1 Jun 2019

Binley A (2015) Tools and techniques: DC electrical methods. In: Schubert G (ed) Treatise on geophysics, 2nd edn, vol 11. Elsevier, Amsterdam, pp 233-259. https://doi.org/10.1016/B978-0444-53802-4.00192-5

Binley A, Hubbard SS, Huisman JA, Revil A, Robinson DA, Singha K, Slater LD (2015) The emergence of hydrogeophysics for improved understanding of subsurface processes over multiple scales. Water Resour Res 51(6):3837-3866

Binley A and Kemna A (2005) DC Resistivity and Induced Polarization Methods. In: Rubin Y, Hubbard SS (eds) Hydrogeophysics. Water Science and Technology Library, vol 50. Springer, Dordrecht. https://doi.org/10.1007/1-4020-3102-5_5

Bogena HR, Huisman JA, Güntner A, Hübner C, Kusche J, Jonard F, Vey J, Vereecken H (2015) Emerging methods for noninvasive sensing of soil moisture dynamics from field to catchment scale: A review. Wiley Interdiscip Rev Water 2(6):635-647

Brindt N, Rahav M, Wallach R (2019) ERT and salinity-a method to determine whether ERT-detected preferential pathways in brackish water-irrigated soils are water-induced or an artifact of salinity. J Hydrol 574:35-45

Bronick CJ, Lal R (2005) Soil structure and management: a review. Geoderma 124(1-2):3-22

Cameira MR, Fernando RM, Pereira LS (2003) Soil macropore dynamics affected by tillage and irrigation for a silty loam alluvial soil in southern Portugal. Soil Tillage Res 70(2):131-140

Campbell GS, Norman JM (1998) Water flow in soil. In: An introduction to environmental biophysics. Springer, New York

Caselles-Osorio A, García J (2006) Performance of experimental horizontal subsurface flow constructed wetlands fed with dissolved or particulate organic matter. Water Res 40(19):3603-3611

Cassiani G, Boaga J, Vanella D, Perri MT, Consoli S (2015) Monitoring and modelling of soil-plant interactions: the joint use of ERT, sap flow and eddy covariance data to characterize the volume of an orange tree root zone. Hydrol Earth Syst Sci 19(5):2213-2225

Consoli S, O'Connell N, Snyder R (2006) Measurement of light interception by navel orange orchard canopies: case study of Lindsay, California. J Irrig Drain E ASCE 132(1):9-20

Consoli S, Papa R (2013) Corrected surface energy balance to measure and model the evapotranspiration of irrigated orange orchards in semi-arid Mediterranean conditions. Irrig Sci 31:1159-1171. https://doi.org/10.1007/s00271-012-0395-4

Consoli S, Stagno F, Roccuzzo G, Cirelli GL, Intrigliolo F (2014) Sustainable management of limited water resources in a young orange orchard. Agric Water Manag 132:60-68

Consoli S, Stagno F, Vanella D, Boaga J, Cassiani G, Roccuzzo G (2017) Partial root-zone drying irrigation in orange orchards: effects on water use and crop production characteristics. Eur $\mathbf{J}$ Agron 82:190-202

D’Emilio A, Aiello R, Consoli S, Vanella D, Iovino M (2018) Artificial neural networks for predicting the water retention curve of sicilian agricultural soils. Water 10(10):1431

Elaiuy ML, Santos LND, Sousa A, Souza CF (2015) Wet bulbs from the subsurface drip irrigation with water supply and treated sewage effluent. Engenharia Agríc 35(2):242-253

Fereres E, Pruitt WO, Beutel JA, Henderson DW, Holzapfel E, Schulbach H, Uriu K (1981) Evapotranspiration and drip irrigation scheduling. In: Drip irrigation management. University of California, Leaflet, pp. 8-13.

Flo V, Martinez-Vilalta J, Steppe K, Schuldt B, Poyatos R (2019) A synthesis of bias and uncertainty in sap flow methods. Agric Forest Meteorol 271:362-374

García-Tejera O, López-Bernal Á, Orgaz F, Testi L, Villalobos FJ (2017) Analysing the combined effect of wetted area and irrigation volume on olive tree transpiration using a SPAC model with a multi-compartment soil solution. Irrig Sci 35(5):409-423

Geuzaine C, Remacle JF (2009) Gmsh: a three-dimensional finite element mesh generator with built-in pre- and post-processing facilities. Int J Numer Methods Eng 79(11):1309-1331

Guo L, Liu Y, Wu GL, Huang Z, Cui Z, Cheng Z, Zhang RQ, Tian FP, $\mathrm{He} \mathrm{H}$ (2019) Preferential water flow: influence of alfalfa (Medicago sativa $\mathrm{L}$.) decayed root channels on soil water infiltration. J Hydrol 578:124019 
Hardie M, Ridges J, Swarts N, Close D (2018) Drip irrigation wetting patterns and nitrate distribution: comparison between electrical resistivity (ERI), dye tracer, and 2D soil-water modelling approaches. Irrig Sci 36(2):97-110

Ibrahim MM, Aliyu J (2016) Comparison of methods for saturated hydraulic conductivity determination: field, laboratory and empirical measurements (a preview). Curr J Appl Sci Technol 15(3):1-8. https://doi.org/10.9734/BJAST/2016/24413

Intrigliolo DS, Castel JR (2007) Evaluation of grapevine water status from trunk diameter variations. Irrig Sci 26:49-59. https://doi. org/10.1007/s00271-007-0071-2

Intrigliolo DS, Lakso AN, Piccioni RM (2009) Grapevine cv. 'Riesling' water use in the northeastern United States. Irrig Sci 27:253-262. https://doi.org/10.1007/s00271-008-0140-1

Jayawickreme DH, Jobbágy EG, Jackson RB (2014) Geophysical subsurface imaging for ecological applications. New Phytol 201(4):1170-1175

Klepper B (1991) Crop root system response to irrigation. Irrig Sci 12(3):105-108

Longo-Minnolo G, Vanella D, Consoli S, Intrigliolo DS, RamírezCuesta JM (2020) Integrating forecast meteorological data into the ArcDualKc model for estimating spatially distributed evapotranspiration rates of a citrus orchard. Agric Water Manag 231:105967

Mary B, Vanella D, Consoli S, Cassiani G (2019) Assessing the extent of citrus trees root apparatus under deficit irrigation via multi-method geo-electrical imaging. Sci rep 9(1):1-10

Mares R, Barnard HR, Mao D, Revil A, Singha K (2016) Examining diel patterns of soil and xylem moisture using electrical resistivity imaging. J Hydrol 536:327-338

Moreno Z, Arnon-Zur A, Furman A (2015) Hydro-geophysical monitoring of orchard root zone dynamics in semi-arid region. Irrig Sci 33(4):303-318

Motisi A, Rossi F, Consoli S, Papa R, Minacapilli M, Rallo G, Cammalleri C, D'Urso G (2012) Eddy covariance and sap flow measurement of energy and mass exchanges of woody crops in a mediterranean environment. Acta Hortic 951:121-127. https ://doi.org/10.17660/ActaHortic.2012.951.14

NAVFAC (1986) Soil mechanics. Design manual 7.01. Naval Facilities Engineering Command: Alexandria, Virginia (USA) pp. 389

Pedescoll A, Uggetti E, Llorens E, Granés F, García D, García J (2009) Practical method based on saturated hydraulic conductivity used to assess clogging in subsurface flow constructed wetlands. Ecol Eng 35(8):1216-1224

Puglisi I, Nicolosi E, Vanella D, Lo Piero AR, Stagno F, Saitta D, Roccuzzo G, Consoli S, Baglieri A (2019) Physiological and biochemical responses of orange trees to different deficit irrigation regimes. Plants 8(10):423

Robinson DA, Campbell CS, Hopmans JW, Hornbuckle BK, Jones SB, Knight R, Ogden F, Selker J, Wendroth O (2008) Soil moisture measurements for ecological and hydrological watershed scale observatories: a review. Vadose Zone J 7:358-389

Robinson JL, Slater LD, Schäfer KVR (2012) Evidence for spatial variability in hydraulic redistribution within an oak-pine forest from resistivity imaging. J Hydrol 430-431:69-79. https://doi. org/10.1016/j.jhydrol.2012.02.002

Ronczka M, Rücker C, Günther T (2015) Numerical study of longelectrode electric resistivity tomography-accuracy, sensitivity, and resolution. Geophysics 80(6):E317-E328

Rossi R, Amato M, Bitella G, Bochicchio R (2013) Electrical resistivity tomography to delineate greenhouse soil variability. Int Agrophys 27(2):211-218

Saitta D, Vanella D, Ramírez-Cuesta JM, Longo-Minnolo G, Ferlito F, Consoli S (2020) Comparison of orange orchard evapotranspiration by eddy covariance, sap flow, and FAO-56 methods under different irrigation strategies. J Irrig Drain E ASCE 146(7):05020002

Samoüelian A, Cousin I, Tabbagh A, Bruand A, Richard G (2005) Electrical resistivity survey in soil science: a review. Soil Till Res 83:173-193

Schwartz BF, Schreiber ME, Yan T (2008) Quantifying field-scale soil moisture using electrical resistivity imaging. J Hydrol 362(34):234-246. https://doi.org/10.1016/j.jhydrol.2008.08.027

Singha K, Day-Lewis FD, Johnson T, Slater LD (2015) Advances in interpretation of subsurface processes with time-lapse electrical imaging. Hydrol Process 29(6):1549-1576

Vanella D, Consoli S (2018) Eddy Covariance fluxes versus satellitebased modelisation in a deficit irrigated orchard. Ital J Agrometeorol 23(2):41-52. https://doi.org/10.19199/2018.2.2038-5625.041

Vanella D, Cassiani G, Busato L, Boaga J, Barbagallo S, Binley A, Consoli S (2018) Use of small scale electrical resistivity tomography to identify soil-root interactions during deficit irrigation. $\mathrm{J}$ Hydrol 556:310-324

Vanella D, Ramírez-Cuesta JM, Intrigliolo DS, Consoli S (2019) Combining electrical resistivity tomography and satellite images for improving evapotranspiration estimates of citrus orchards. Remote Sens 11(4):373

Vereecken H, Huisman JA, Bogena H, Vanderborght J, Vrugt JA, Hopmans JW (2008) On the value of soil moisture measurements in vadose zone hydrology: a review. Water Resour Res 44:1-21

Williams MR, Buda AR, Singha K, Folmar GJ, Elliott HA, Schmidt JP (2017) Imaging hydrological processes in headwater riparian seeps with time-lapse electrical resistivity. Groundwater 55(1):136-148

Wu GL, Liu Y, Yang Z, Cui Z, Deng L, Chang XF, Shi ZH (2017) Root channels to indicate the increase in soil matrix water infiltration capacity of arid reclaimed mine soils. J Hydrol 546:133-139

Zhang Y, Niu J, Zhang M, Xiao Z, Zhu W (2017) Interaction between plant roots and soil water flow in response to preferential flow paths in northern China. Land Degrad Dev 28(2):648-663

Zhang SY, Hopkins I, Guo L, Lin H (2019) Dynamics of infiltration rate and field-saturated soil hydraulic conductivity in a wastewater-irrigated cropland. Water 11(8):1632

Publisher's Note Springer Nature remains neutral with regard to jurisdictional claims in published maps and institutional affiliations. 